\title{
SISTEM PENDUKUNG KEPUTUSAN PEMILIHAN BAHAN BAKU ALUMUNIUM MENGGUNAKAN METODE VISEKRITERIJUMSKO KOMPROMISNO RANGIRANJE
}

\author{
Agusta Praba Ristadi Pinem ${ }^{1}$, Aria Hendrawan ${ }^{2}$, Mega Sekar Sari $^{3}$ \\ ${ }^{1,2,3}$ Program Studi Sistem Informasi Fakultas Teknologi Informasi dan Komunikasi Universitas Semarang \\ Jl. Soekarno Hatta, Tlogosari Kulon, Kota Semarang \\ 1 agusta.pinem@usm.ac.id \\ 2ariahendrawan@usm.ac.id \\ ${ }^{3}$ megasekar0107@gmail.com
}

\begin{abstract}
Abstrak
Supplier bahan baku yang berkualitas baik, dapat membantu dalam ketrampilan proses pembuatan meubel dalam persaingan penjualan meubel, berdampak pada evaluasi penentuan supplier bahan baku, tidak mengalami kekecewaan dalam memilih barang. Begitu pula dengan Meubel Sulkani Putra Alumunium yang memproduksi dan menjual perabotan meubel rumah tangga. Pemilihan supplier bahan baku, dilakukan oleh pemilik meubel yang masih mengalami kesulitan, dalam menentukan alternatif terbaik, karena begitu banyak kriteria penentu yang di pertimbangkan, serta membutuhkan pengambilan keputusan yang akurat dan tepat sasaran. Permasalah tersebut, Meubel Sulkani Putra Alumunium membutuhkan Sistem Pendukung Keputusan (SPK) dalam menentukan supplier bahan baku. Metode SPK yang digunakan dalam penelitian adalah Vlse Kriterijumska Optimizacija I Kompromisno Resenje (VIKOR). Pada penelitian kali ini kriteria yang digunakan adalah harga barang, waktu pemesanan, respon pemesanan, kualitas, garansi, jatuh tempo dan diameter/ketebalan. Metode ini berfokus pada perangkingan dan memilih dari satu set alternatif, dan menentukan solusi yang dapat membantu para pengambil keputusan untuk mencapai keputusan akhir. Hasil dari penelitian dengan pengujian menggunakan metode korelasi rank spearman menunjukan bahwa metode VIKOR memiliki nilai keeratan 0.8 dengan fakta penilain supplier bahan baku aluminium.
\end{abstract}

Kata kunci: Sistem Pendukung Keputusan, Supplier Bahan Baku, VIKOR

\section{PENDAhUluan}

Meubel Sulkani Putra Alumunium yang berlokasi di Jl. Kedung Mundu Raya 25 Semarang. Merupakan sebuah toko yang memproduksi dan penjualan barang-barang meubel berskala kecil menengah. Dampak dari beragam permintaan konsumen menyebabkan Meubel Sulkani Putra Almunium harus selalu menyediakan dan memberikan pelanyanan terbaik bagi konsumen.

Dalam usaha yang di lakukan, Meubel Sulkani Putra Alumunium melakukan berbagai cara untuk menenangkan persaingan dimata konsumen, diantaranya meningkatkan kepuasan pelanggan dengan produk yang berkualitas, ketepatan waktu dalam proses pengiriman barang. Hal tersebut terhubung dengan proses pemilihan pemasok bahan baku. Pemilihan pemasok menjadi salah satu hal yang penting, karena sangat berpengaruh terhadap harga jual dan ketersedian suatu produk yang diminati oleh konsumen.

Sistem pendukung keputusan (SPK) salah satu metode yang dapat memberikan solusi dalam penentuan pilihan [1]. Salah satu bagian dari SPK yaitu Mutli-Criteria Decision Making (MCDM) telah banyak digunakan dalam membantu proses pengambilan keputusan yang berkaitan dengan masalah yang rumit dan sukar untuk diukur secara pasti [2]. MCDM fokus pada pengambilan keputusan yang dapat dilakukan oleh banyak pihak dengan mempertimbangkan kritera-kriteria yang 
menjadi indikator berdasarkan skala keterpengaruhan [3] Teknik MCDM adalah metode sistematis yang secara rasional menentukan pentingnya kriteria (yaitu, sifat material) dengan mempertimbangkan aplikasi tertentu dan membuat keputusan tentang kandidat material yang paling tepat dan menghilangkan alternatif yang tidak sesuai [4]. Model MCDM telah banyak dimanfaatkan dalam pengambilan keputusan untuk beberapa kasus baik sosial, ekonomi dsb [5].

Pemanfaatan metode MCDM pada objek penentuan pemasok sudah banyak dilakukan, antara lain penentuan green supplier pada bidang manufaktur dengan menggunakan metode WASPAS [6] [7] [8], pemilihan pemasok dengan metode ELECTRE [9] dan menggunakan metode MOORA [10].

Metode Vlse Kriterijumska Optimizacija I Kompromisno Resenje (VIKOR) termasuk dalam model MCDM [4]. Metode VIKOR memiliki kemampuan analisis yang lebih cepat, memori yang lebih sedikit, dan akurasi yang lebih baik daripada metode lainnya [11]. Pada penelitian sebelumnya memanfaatkan metode VIKOR untuk penentuan Badan Usaha Milik Desa [12], pemasok bahan baku garmen [13], penerima bantuan Covid-19 [14], karyawan terbaik pada bidang usaha teknologi informasi [15], alat musik keyboard electone [16] dan apoteker terbaik [17].

Tujuan penelitian ini adalah mengembangkan Sistem Pendukung Keputusan Pemilihan Pemasok Bahan Baku Alumunium Menggunakan Metode VIKOR. Hasil metode VIKOR kemudian dibandingkan dengan data primer yang diperoleh dalam observasi dan wawancara dengan pengguna bahan baku menggunakan metode korelasi rank spearman. Sehingga memunculkan validitas dari metode VIKOR.

\section{Metodologi PENELITIAN}

Tahapan-tahapan penelitian yang dilaksanakan meliputi Studi Literatur, Identifikasi Masalah, Pengumpulan Data, Penentuan Kriteri dan Bobot, Penentuan Metode, Pengembangan Sistem, Uji Korelasi atau ditunjukan pada gambar 1 dibawah ini.

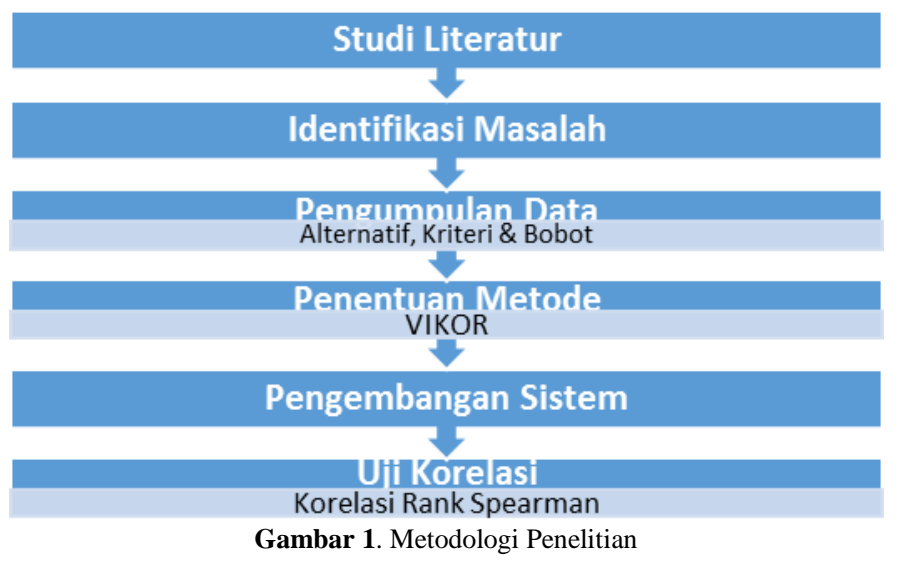

Tahapan pengumpulan data menghasilkan data alternative dan kriteria yang digunakan. Dalam menentukan pemilihan pemasok bahan baku aluminium menggunakan kriteria table 1 .

Tabel 1. Kriteria Pemilihan Pemasok Bahan Baku Alumunium.

\begin{tabular}{lcl}
\multicolumn{1}{c}{ KrITERIA } & Bobot & \multicolumn{1}{c}{ Keterangan } \\
\hline Harga Barang & 85 & Kecil Lebih Baik (-1) \\
\hline Waktu Pemesanan & 95 & Kecil Lebih Baik (-1) \\
\hline Respon Pemesanan & 80 & Kecil Lebih Baik (-1) \\
\hline Kualitas & 95 & Besar Lebih Baik (1) \\
\hline Garansi & 75 & Besar Lebih Baik (1) \\
\hline Jatuh Tempo & 65 & Besar Lebih Baik (1) \\
\hline Diamter/Ketebalan & 90 & Kecil Lebih Baik (-1) \\
\hline
\end{tabular}

Keseluruhan bobot harus bernilai 1. Sedangkan untuk menentukan nilai min/max didalam kriteria adalah jika nilai alternatif yang dicari adalah nilai tertinggi semakin baik, maka hasil nilai $\mathrm{min} / \max$ kriteria $=1$ (positi). Tetapi jika nilai alternatif yang dicari adalah terendah semakin baik, maka hasil nilai $\mathrm{min} / \mathrm{max}$ kriteria $=-1$ (negatif).

Metode VIKOR memiliki langkah-langkah berikut

Adapun langkah-langkah dalam perhitungan dengan menggunakan metode VIKOR antara lain :

1. Menetukan Bobot kriteria dan nilai min/max kriteria menggunakan rumus sebagai berikut :

$\mathrm{W}_{\mathrm{j}=1}$

2. Melakukan cara normalisali dengan menggunakan rumus sebagai berikut :

$R_{\mathrm{ij}}=\left(\frac{x j^{\top}-x_{i y}}{x j^{+}-x j-}\right)$

3. Melakukan cara menghitung nilai $\mathrm{S}$ dan $\mathrm{R}$ dengan menggunakan rumus sebagai berikut :

$S_{i}=\sum_{j=i}^{n} W_{j}\left(\frac{x^{+j i j}-x_{i j}}{x^{+j}-x^{-j}}\right)$

Dan

$\operatorname{Max} j\left[W_{j}\left(\frac{x^{+j}-x_{i j}}{x^{+j}-x^{-j}}\right)\right]$

4. Melakukan cara menentukan nilai indeks dengan rumus sebagai berikut

$Q_{\mathrm{i}}\left[\frac{Q_{\mathrm{i}-s^{+}}}{s^{+}-s^{-}}\right] v+\left[\frac{R_{\mathrm{i}-R^{*}}}{R^{+-R^{*}}}\right](1-v)$

Hasil perangkingan merupakan hasil pengurutan $S, R$ dan Q. Solusi alternatif peringkat terbaik berdasarkan dengan nilai $\mathrm{Q}$ minimum menjadi peringkat terbaik dengan syarat :

$\mathrm{Q}\left(\mathrm{A}^{(2)}\right)-\mathrm{Q}\left(\mathrm{A}^{(1)}\right) \geq \mathrm{DQ}$

Dimana

$\mathrm{A}^{(2)}=$ alternatif dengan urutan kedua pada perangkingan Q dan

A (1) = alternatif dengan urutan terbaik pada perangkingan $\mathrm{Q}$

Sedangkan

DQ $=1-(\mathrm{M}-1)$ 
dimana m merupakan jumlah alternatif.

Alternatif $\mathrm{A}^{(1)}$ harus berada pada rangking terbaik pada $\mathrm{S}$ dan/atau R.

Sedangkan dalam melakukan uji korelasi menggunakan persamaan Kolerasi Rank Spearman:

$$
r_{x y}=1-\frac{6 \sum_{1=1}^{n} d_{i}^{2}}{n\left(n^{2}-1\right)}
$$

$\mathrm{r}_{\mathrm{xy}} \quad=$ Koefisien Korelasi Rank Spearman

$\mathrm{d}=$ Selisih rangking / peringkat antara $\mathrm{x}$ dan $\mathrm{y}$

$\mathrm{n} \quad=$ Banyak subjek pengamatan

\section{HASIL DAN PEMBAHASAN}

\subsection{Perancangan}

Use case diagram digunakan untuk mengetahui tentang fungsi apa saja yang ada di dalam sistem, di tunjukkan pada Gambar ke 2.

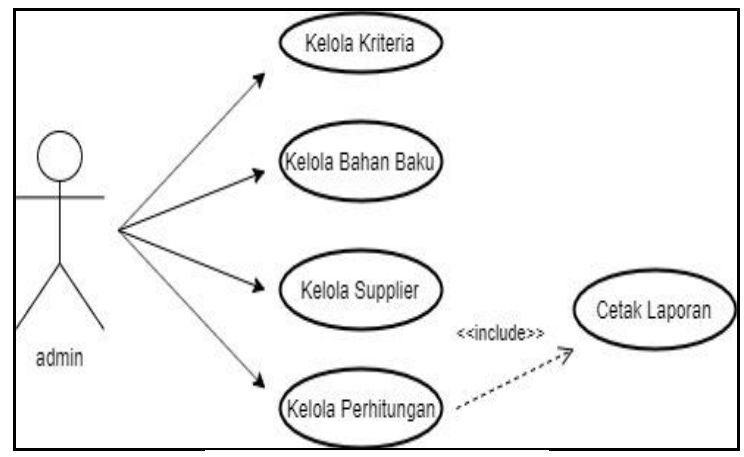

Gambar 2. Use Case Diagram

Pada Gambar 2 use case diagram menggambarkan suatu aktor yang menjalankan sistem yang bertugas untuk mengelola kriteria, bahan baku, supplier dan mengelola perhitungan.

Class diagram sistem menggambarkan struktur sistem yang berisi tentang atribut, perilaku, dan kelas yang saling berhubungan dengan objek untuk membangun sistem, ditunjukkan pada Gambar ke 3.

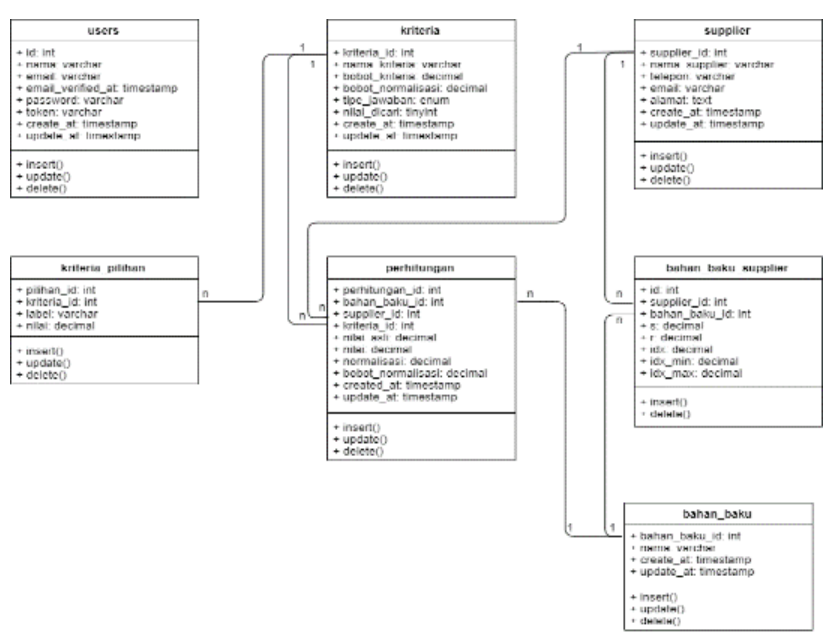

Gambar 3. Class Diagram
Pada Gambar 3 class diagram menggambarkan relasi antar tabel yang digunakan dalam sistem pendukung keputusan pemilihan supplier bahan baku dengan semua relasi yang ada didalam sistem.

\subsection{Implementasi Sistem}

Berikut ini adalah tampilan pada halaman menu perhitungan yang terdapat pada Gambar ke 4.

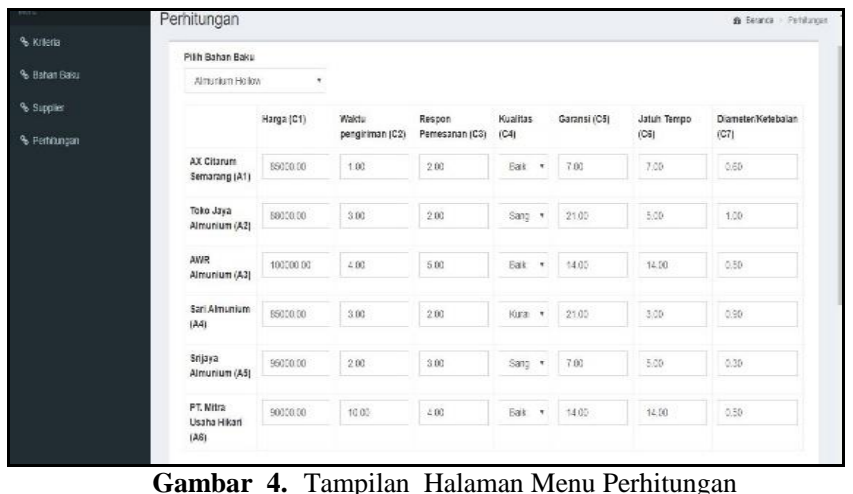

Pada Gambar ke 4 merupakan tampilan menu perhitungan, digunakan untuk melakukan proses perhitungan menggunakan metode VIKOR dengan mengimplementasikan persamaan kedalam algoritma program PHP.

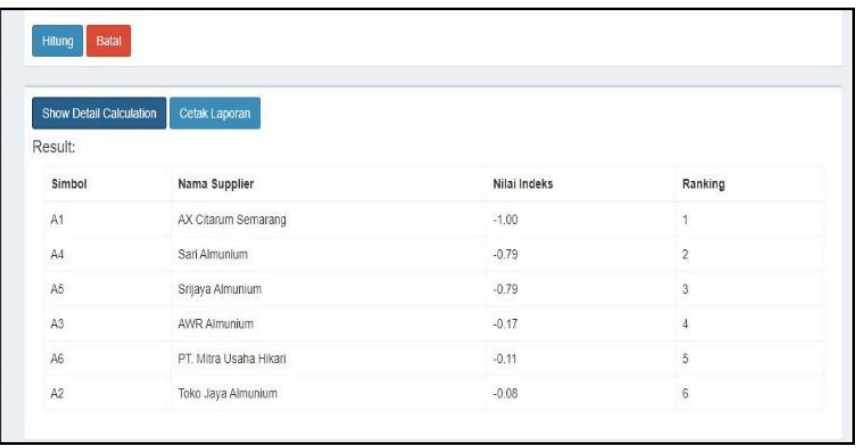

Gambar 5. Tampilan Halaman Hasil Perangkingan

Gambar 5 merupakan halaman hasil perangkingan atau output system berdasarkan nilai indeks metode VIKOR. Berdasarkan output system, alternative A1 menempati rangking 1 dan A4 menempati rangking $2 \mathrm{dst}$.

\subsection{Perhitungan VIKOR}

Dalam mengembankan SPK perlu melakukan dua pengujian, yaitu pengujian membandingkan hasil output system dengan perhitungan manual untuk memastikan algoritma metode VIKOR sudah diterjemahkan kedalam bahasa pemrograman dengan benar. Sedangkan pengujian selanjutnya adalah uji korelasi hasil metode VIKOR dengan data fakta.

Proses awal pada metode VIKOR adalah menentukan normalisasi dari matrik keputusan dengan menarik data 
kriteria setiap alternative yang digunakan. Berikut hasil normalisasi matrik keputusan.

$$
\mathrm{W} \text { (nilai bobot) }=\left(\begin{array}{ccccccc}
0.15 & 0.16 & 0.14 & 0.16 & 0.13 & 0.11 & 0.15
\end{array}\right)
$$

Hasil normalisasi matrik keputusan kemudian dikalikan dengan bobot masing-masing kriteri untuk mendapatkan nilai matrik keputusan normalisasi terbobot yang selanjutnya digunakan untuk menentukan nilai $\mathrm{S}$ dan $\mathrm{R}$.

Ketika tahapan penentukan nilai $\mathrm{S}$ dan $\mathrm{R}$ selesai, maka langkah selanjutnya adalah menentukan nilai indeks VIKOR (Qi). Berikut hasil perhitungan indeks VIKOR (Qi) dengan nilai $\mathrm{v}=0,5$.

$$
\begin{aligned}
& \mathrm{Q} 1=0.5\left(\frac{0.31-0.50}{0.50-0.91}\right)+(1-0.5)\left(\frac{0.12-0.16}{0.16-0.19}\right)=-1.00 \\
& \text { Q2 }=0.5\left(\frac{0.47-0.50}{0.50-0.31}\right)+(1-0.5)\left(\frac{0.16-0.16}{0.16-0.19}\right)=-0.08 \\
& \text { Q3 }=0.5\left(\frac{0.50-0.50}{0.50-0.91}\right)+(1-0.5)\left(\frac{0.15-0.16}{0.16-0.19}\right)=-0.17 \\
& \text { Q4 }=0.5\left(\frac{0.39-0.50}{0.50-0.91}\right)+(1-0.5)\left(\frac{0.12-0.16}{0.16-0.13}\right)=-0.79 \\
& \text { Q5 }=0.5\left(\frac{0.39-0.50}{0.50-0.91}\right)+(1-0.5)\left(\frac{0.12-0.16}{0.16-0.13}\right)=-0.79 \\
& \text { Q6 }=0.5\left(\frac{0.46-0.50}{0.50-0.31}\right)+(1-0.5)\left(\frac{0.16-0.16}{0.16-0.19}\right)=-0.11
\end{aligned}
$$

Menentukan peringkat pemasok terbaik berdasarkan Nilai Q Minimum. Hasil perhitungan sistem dan manual ditunjukan

\begin{tabular}{|c|c|c|c|c|}
\hline Supplier & $\begin{array}{c}\text { Ranking } \\
\text { Meubel (X) }\end{array}$ & $\begin{array}{c}\text { Ranking } \\
\text { VIKOR (Y) }\end{array}$ & $\begin{array}{l}\mathrm{d} \\
\mathrm{x}-\mathrm{y}\end{array}$ & $\begin{array}{l}\mathrm{d}^{2} \\
\mathrm{xy}^{2}\end{array}$ \\
\hline (A1) & 1 & 1 & 0 & 0 \\
\hline (A2) & 4 & 6 & -2 & 4 \\
\hline (A3) & 5 & 4 & 1 & 1 \\
\hline (A4) & 3 & 2 & 1 & 1 \\
\hline (A5) & 2 & 2 & 0 & 0 \\
\hline (A6) & 6 & 5 & 1 & 1 \\
\hline Total
\end{tabular}

pada tabel 2 .

Tabel 2. Hasil Perangkingan Perhitungan Manual VIKOR

\begin{tabular}{ccccc}
\hline \multirow{2}{*}{ Alternatif } & \multicolumn{2}{c}{ Hasil Manual } & \multicolumn{2}{c}{ Output Sistem } \\
\cline { 2 - 5 } & Nilai Q & Rank & Nilai Q & Rank \\
\hline (A1) & -1.00 & 1 & -1.00 & 1 \\
\hline (A2) & -0.08 & 6 & -0.08 & 6 \\
\hline (A3) & -0.17 & 4 & -0.17 & 4 \\
\hline (A4) & -0.79 & 2 & -0.79 & 2 \\
\hline (A5) & -0.79 & 3 & -0.79 & 3 \\
\hline (A6) & -0.11 & 5 & -0.11 & 5 \\
\hline
\end{tabular}

Tabel 2 merupakan hasil perhitungan metode VIKOR secara manual dan berdasarkan output system yang dikembangkan. Hasil diatas menunjukan system telah menghasilkan outuput yang sesuai dengan perhitungan manual, hal ini ditunjukan pada hasil nilai $Q$ pada table 2. Maka metode VIKOR telah diimplementasikan dengan benar menjadi algoritma dengan menggunakan bahasa pemrograman PHP.

\subsection{Uji Korelasi}

Hasil grafik Ranking Meubel dan Ranking menggunakan metode VIKOR. Berikut adalah hasil grafik perbandingan ranking yang terdapat pada Gambar ke 6.

\section{GRAFIK PERBANDINGAN RANKING}

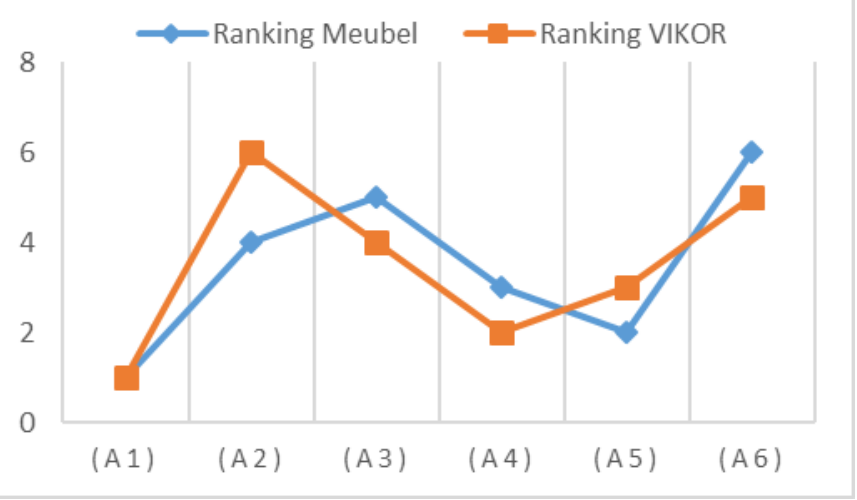

Gambar ke 6. Hasil grafik perbandingan ranking

Pada Gambar ke 6 merupakan hasil grafik pada meubel menunjukkan bahwa hasil perangkingan pertama terdapat pada alternatif A1 dan peringkat terakhir pada A6. Sedangkan pada hasil grafik pada sistem VIKOR menunjukkan bahwa hasil perangkingan pertama terdapat $\mathrm{A} 1$ dan peringkat terakhir pada A2.

Hasil grafik pada gambar 6 belum dapat digunakan untuk menarik kesumpulan secara obyektif. Pada penjelasan diatas, penelitian ini menggunaan metode korelasi rank spearman untuk mengukur tingkat kesesuaian rangking yang dihasilkan metode VIKOR dengan fakta pengguna bahan baku aluminium. Berikut proses perhitungan korelasi rank spearman.

Tabel 3. Hasil perhitungan Rank Spearman

\begin{tabular}{|l|l|l|l|}
\hline $6 \Sigma \mathrm{d}^{2}$ & $\mathrm{~N}\left(\mathrm{~N}^{2}-1\right)$ & $6 \Sigma \mathrm{d}^{2} / \mathrm{N}\left(\mathrm{N}^{2}-1\right)$ & $\mathrm{R}$ \\
\hline 42 & 210 & 0,2 & 0,8 \\
\hline
\end{tabular}

Table 3 hasil perhitungan rank spearman menunjukan bahwa nilai korelasi antaran ranking yang ditentukan oleh pengguna dan rangking berdasarkan metode VIKOR sebedar 0,8 . Hal ini menunjukan metode VIKOR dapat digunakan untuk menentukan pemasok bahan baku aluminium berdasarkan kriteria yang digunakan.

\section{KESIMPULAN}

Berdasarkan hasil pembahasan didapatkan hasil bahwa sistem pendukung keputusan pemilihan supplier bahan baku alumunium menggunakan metode VIKOR memiliki nilai korelasi rank spearman sebesar 0,8 yang artinya dapat dikatakan erat atau saling berhubungan dengan data fakta penilaian pengguna bahan baku. Atau dengan kata lain metode 
VIKOR dapat digunakan untuk menentukan pemasok bahan baku alumunium dengan menggunakan 7 kriteria.

\section{SARAN}

Dalam pengembangan selanjutnya, dapat ditambahkan kombinasi metode SPK untuk menentukan bobot kriteria. Sehingga nilai bobot berasal dari lebih dari satu pengambil keputusan.

\section{REFERENSI}

[1] S. Bid and G. Siddique, "Human risk assessment of Panchet Dam in India using TOPSIS and WASPAS Multi-Criteria Decision-Making (MCDM) methods," Heliyon, vol. 5, no. 6, p. e01956, Jun. 2019, doi: 10.1016/j.heliyon.2019.e01956.

[2] "Implementasi Multi Criteria Decision Making (Mcdm) Pada Agroindustri: Suatu Telaah Literatur," j.tek.ind.pert., pp. 234-343, Sep. 2020, doi: 10.24961/j.tek.ind.pert.2020.30.2.234

[3] M. Deveci, F. Canıtez, and I. Gökaşar, "WASPAS and TOPSIS based interval type-2 fuzzy MCDM method for a selection of a car sharing station," Sustainable Cities and Society, vol. 41, pp. 777-791, Aug. 2018, doi: 10.1016/j.scs.2018.05.034.

[4] S. Dev, A. Aherwar, and A. Patnaik, "Material Selection for Automotive Piston Component Using Entropy-VIKOR Method," Silicon, vol. 12, no. 1, pp. 155-169, Jan. 2020, doi: 10.1007/s12633-019-00110-y.

[5] C. R. Matawale, S. Datta, and S. S. Mahapatra, "Supplier selection in agile supply chain: Application potential of FMLMCDM approach in comparison with Fuzzy-TOPSIS and Fuzzy-MOORA," Benchmarking: An International Journal, vol. 23, no. 7, pp. 2027-2060, Oct. 2016, doi: 10.1108/BIJ-07-2015-0067.

[6] A. R. Mishra, P. Rani, K. R. Pardasani, and A. Mardani, "A novel hesitant fuzzy WASPAS method for assessment of green supplier problem based on exponential information measures," Journal of Cleaner Production, vol. 238, p. 117901, Nov. 2019, doi: 10.1016/j.jclepro.2019.117901.

[7] G. Stojić, Ž. Stević, J. Antuchevičienè, D. Pamučar, and M. Vasiljević, "A Novel Rough WASPAS Approach for Supplier Selection in a Company Manufacturing PVC Carpentry Products," Information, vol. 9, no. 5, p. 121, May 2018, doi: 10.3390/info9050121.

[8] M. Keshavarz Ghorabaee, E. K. Zavadskas, M. Amiri, and A. Esmaeili, "Multi-criteria evaluation of green suppliers using an extended WASPAS method with interval type-2 fuzzy sets," Journal of Cleaner Production, vol. 137, pp. 213-229, Nov. 2016, doi: 10.1016/j.jclepro.2016.07.031.

[9] M. Sevkli, "An application of the fuzzy Electre method for supplier selection," International Journal of Production Research, vol. 48, no. 12, pp. 3393-3405, Jun. 2010, doi: 10.1080/00207540902814355.
[10] A. Arabsheybani, M. M. Paydar, and A. S. Safaei, "An integrated fuzzy MOORA method and FMEA technique for sustainable supplier selection considering quantity discounts and supplier's risk," Journal of Cleaner Production, vol. 190, pp. 577-591, Jul. 2018, doi: 10.1016/j.jclepro.2018.04.167.

[11] J. Hu, X. Zhang, Y. Yang, Y. Liu, and X. Chen, "New doctors ranking system based on VIKOR method," Intl. Trans. in Op. Res., vol. 27, no. 2, pp. 1236-1261, Mar. 2020, doi: 10.1111/itor.12569.

[12] M. Rizky, "Sistem Pendukung Keputusan Penentuan Badan Usaha Milik Desa Terbaik Menerapkan Metode VIKOR," vol. 2, p. 8, 2021.

[13] D. M. Utama, "Penyelesaian Green Supplier Selection Menggunakan Integrasi AHP DAN VIKOR,” p. 7, 2020.

[14] S. P. Lengkong, "Decision Support System for Covid19 Aid Recipients using VIKOR method," p. 6, 2020.

[15] M. Handayani and N. Marpaung, "Implementasi Metode Vikor Sebagai Pendukung Keputusan Penentuan Karyawan Penerima Reward," p. 9.

[16] A. Arisandi and E. S. Pribadi, "Analisa Metode VIKOR pada Rekomendasi Alat Musik Keyboard Electone Terbaik," KESATRIA, vol. 1, no. 1, pp. 31-36, Feb. 2020, doi: 10.30645/kesatria.v1i1.14.

[17] A. Kusuma and G. Ginting, "Sistem Pendukung Keputusan Pemilihan Apoteker Terbaik Pada PT. Kimia Farma (Persero) Tbk Medan Menerapkan Metode Vikor," json, vol. 1, no. 3, p. 252, May 2020, doi: 10.30865/json.v1i3.2163. 